\title{
Ecological Civilization Construction Strategies in the Tianshan Mountain Northern Slope Economic Belt
}

\author{
Yang Rongjin ${ }^{1}$, Meng Wei ${ }^{1}$, Duan Ning ${ }^{1}$, Shu Jianmin ${ }^{1}$, Zhang Huiyuan ${ }^{1}$, Jiaerheng·Ahati ${ }^{2}$, Wang Hao ${ }^{3}$, Zhang \\ Linbo $^{1}$, Qiao Qi $^{1}$, Yin Weilun ${ }^{4}$, Zhang Qiang ${ }^{1}$, Sun Meiying ${ }^{5}$ \\ 1. State Key Laboratory of Environmental Criteria and Risk Assessment, Chinese Research Academy of Environmental Sciences, Beijing 100012, \\ China \\ 2. Xinjiang Academy of Environmental Protection Science, Urumqi 830011, China \\ 3. China Institute of Water Resources and Hydropower Research, Beijing 100038, China \\ 4. Beijing Forestry University, Beijing 100083, China \\ 5. Beijing Normal University, Beijing 100875, China
}

\begin{abstract}
To promote the national ecological civilization construction strategy and the Belt and Road strategy, the Chinese Research Academy of Environmental Sciences conducted a project titled "Ecological Civilization Construction Strategies in the Tianshan Mountain Northern Slope Economic Belt" in 2014-2016. Based on the vision for the Silk Road Economic Belt, as well as the regional positioning and actual development of the Tianshan Mountain Northern Slope Economic Belt, six strategies are proposed: (1) an optimization strategy for land spatial patterns; (2) an optimal allocation and sustainable development strategy for regional resources; (3) a green development strategy for the industrial economy; (4) a priority strategy for ecological and environmental protection; (5) a reform and innovation strategy for systems and mechanisms; and (6) a westward opening strategy. This study provides decisionmaking support to accelerate ecological civilization construction in western China, promote the extension of the green Silk Road Economic Belt, and implement the 13th Five-Year Plan for development in western China and for the Tianshan Mountain Northern Slope Economic Belt Development Plan.
\end{abstract}

Keywords: Tianshan Mountain Northern Slope Economic Belt; ecological civilization; Silk Road Economic Belt; regional development; strategic research

Tianshan Mountain Northern Slope Economic Belt is the core area on the Silk Road Economic Belt. The study on its ecological civilization construction strategies is a beneficial exploration of regional ecological civilization construction strategic research and ecological civilization construction strategic research in western China. It provides western China and countries along the Silk Road Economic Belt with useful references for ecological civilization construction, and also to increase the possibility of the concept of Chinese ecological civilization "going out".

\section{Optimization strategy of land spatial framework}

1.1 Implementation of the optimization of the east-west spatial framework and realization of the international and domestic spatial equilibrium

The Second Eurasian Continental Bridge, Alataw Pass, Horgas Pass, west-to-east natural oil and gas transmission

Received date: June 20, 2017; Revised date: July 10, 2017

Corresponding author: Yang Rongjin, Chinese Research Academy of Environmental Sciences, Professor. Major research field is the construction of ecological civilization strategy. E-mail: yangrj@craes.org.cn

Funding program: CAE Advisory Project “Ecological Civilization Construction Strategies in the Tianshan Mountain Northern Slope Economic Belt” (2014-ZD-4) Chinese version: Strategic Study of CAE 2017, 19 (4): 040-047

Cited item: Yang Rongjin et al. Ecological Civilization Construction Strategies in the Tianshan Mountain Northern Slope Economic Belt. Strategic Study of CAE, https://doi.org/10.15302/J-SSCAE-2017.04.007 
pipelines, high-voltage transmission and transformation lines from western areas to east China, and other infrastructures are symbols that indicate that we should fully acknowledge the internal and external role of the Silk Road Economic Belt. By taking advantage of the international and domestic "two kinds of resources" and "two markets" and the characteristics of the Tianshan Mountain Northern Slope Economic Belt-such as insufficient water resources, fragile ecosystem, and insufficient environmental carrying capacity - and based on the export of primary grain and agricultural and mineral products, the structural reform of the supply side can be accelerated. The land space in the Tianshan Mountain Northern Slope Economic Belt will gradually shift from producing low and middle primary products to the processing of middle and high value-added products, commerce, logistics, technology, finance, tourism, education, and other services. We should gradually restore and expand the natural ecological space, reduce the artificial oasis agriculture and industrial and mining space, and expand and promote the tertiary industry which is represented by the service industry.

\subsection{Implementation of the optimization of the north-south spatial framework and realization of the spatial equilibrium around the economic belt and along the upper and lower reaches of the basin}

The Tianshan Mountain Northern Slope Economic Belt should strengthen the coordination of the land and space in southern Xinjiang to continue the exchange of needed goods and realize common development. There remains a wide gap between the development of the Tianshan Mountain Northern Slope Economic Belt and eastern China. We should make full use of related policies such as Counterparts Support Xinjiang and Western Development Strategy. Increasing the introduction and docking of intelligence technology, capital technology, management, and dispatching from central and eastern China is also important. These measures can speed up the transformation and upgrading of the regional industry and improve its quality and efficiency. The space optimization strategy of the south-north Inland River Basin should use water as the medium. To effectively promote the construction of a "landscape forest land lake" life community, we should strengthen the protection and restoration of the ecological space in the upper reaches, optimize the space of urban life, industry, mining, and agricultural production in the middle reaches, and maintain the ecological space of the rivers, lakes, and wetlands in the lower reaches; this could allocate the soil and water resources rationally. Projects should obey and serve the land spatial structure optimization strategies of the Tianshan Mountain Northern Slope Economic Belt, such as "Ertix River to Urumchi" and "Kashi River to Ebinur Lake".
1.3 Implementation of the planning of the main-functional area and promotion of the differential management and control of land space zoning

The expansion of artificial oases should be strictly controlled. Natural oases need protection and restoration to maintain the function of the oasis-desert transitional zone. To maintain the reasonable scale of cultivated land and realize the sustainable utilization of cultivated land, the reduction in cultivated land area and land rehabilitation should be actively promoted. To prevent the disorderly spread of the city and the occupation of the ecological and agricultural production space, the developing boundaries of the urban space should be scientifically controlled. To achieve the dislocation development of the regional industry and the continuous improvement of the urban living environment, the spatial cohesion link between the main-functional area planning of the Xinjiang Uygur Autonomous Region \& Xinjiang production and construction corps (hereinafter referred to as the autonomous region and the corps) and the development planning of the Tianshan Mountain Northern Slope Economic Belt should be actively promoted, as should the link between regional planning and basin planning. The pilot projects of "multiple-plan integration" and the regional "integration of cities and industries" also need to be promoted. We should strengthen the protection of key ecological functional areas, actively promote the delimiting of the ecological redline, and strengthen the management and control of the ecological redline. In addition, we should strengthen the support of the national and autonomous key ecological functional zones or counties, and establish a differential assessment mechanism.

\section{Optimal allocation of resources and strategy of sustainable development}

2.1 Strict control of the total amount of water and the development and utilization of water resources to improve the scientific level of the optimal allocation of water resources

The water consumption per unit gross domestic product (GDP), water consumption per unit industry, and the amount of agricultural water need to be greatly reduced to decrease their proportion of the total water consumption of society and the economy. The scale of high water consumption industries, such as the petrochemical and coal chemical industries, in the middle and eastern segment of the Tianshan Mountain Northern Slope Economic Belt, should be strictly controlled to transform the quality benefit type from the quantity increase to quality benefit. The continuous expansion of cultivated land in severely overmined groundwater areas, severe atrophy areas of terminal rivers and lakes, and severe sandstorm areas should also be strictly controlled. Non-cultivated land and low-yield arable land should 
be gradually returned to grass and forests, and the construction of high-yield fields, farmland water conservancy infrastructures, and farm-shelter forests needs to be increased. We should optimize the planting structure, reduce the planting area of low efficiency and high water consumption crops such as wheat and cotton, and enlarge the planting area of high efficiency and low water consumption fruits and vegetables. The expansion of artificial oases needs to be controlled and areas of natural oases should be expanded to ensure the basic demand for water resources in the oasis-desert transitional zones. The grain output should be reduced and its input increased. We could allocate high water consumption industry by crossing regions, and input water footprints and virtual water. With full consideration of the ecological conservation in water-outputting areas and the environmental capacity of water-receiving areas, we could rationally determine the scale and scope of the water transfer projects from the Ertix River and Kashi River to the middle and eastern section of the Tianshan Mountain Northern Slope Economic Belt. The allocation of water resources should be transformed from life, production, and ecology to life, ecology, and production. The security of the ecological water requirement of fragile ecosystems, the protection of terminal rivers and lakes, and the function of sand fixation and biodiversity conservation need to be strengthened. We should coordinate the allocation of water resources, including those on the ground and underground and the upper, middle, and lower reaches of the river. It is vital to accelerate the return of groundwater to the severely overmined groundwater areas, improve water conservation upstream, control the water for artificial oases, cities, and industries, and guarantee the basic ecological demand in the lower reaches.

\subsection{Strict control of the unordered expansion of construction land, improvement of the quality and benefit of land resources, and strengthening of the protection of ecological land}

The protection and restoration of the vegetation and ecology around industrial and mining land should be strengthened to prevent land degradation and desertification, and to control the hazards of wind sand and the degradation of the vegetation downstream. Mining activities should gradually withdraw from the conservation area of extremely important water resources, biodiversity, water, and soil. We should economize and make intensive use of industrial land, improve the performance of land resource utilization, and rationally lay out industrial land according to environmental capacity and the circular economy industrial system, so as to promote the integration of production and city. We should control the development boundaries of the city to reduce the occupation of the cultivated land, grasslands, and oasis-desert transitional zones. The planning of urban system should be perfected, and prerequisites for establishing new towns or areas should be much stricter to realize green and sustainable urban development. The land demand from industries and areas that are closely related to regional positioning, such as trade, logistics, port, tourism and transportation, should be guaranteed preferentially. We should actively promote the implementation of regional strategic positioning and the rapid and sustainable development of the regional economy. We should strengthen the conservation of water and soil upstream of inland river basins, strictly control disordered mining and overgrazing, promote the orderly withdrawal of small coal mines etc., and implement returning grazing, rest grazing, and grazing prohibition in overgrazed areas. We suggest controlling the excessive expansion of artificial oases in the middle reaches and maintaining a reasonable proportion of natural and artificial oases. In non-cultivated land and oasis-desert transitional zones, the farmland should be return to grasslands and forests with local species that are suitable for the water conditions in this region. We propose ensuring that the water demand of farmland protection forests be met with water-saving irrigation to maintain their functions of windbreak, sand fixation, climate regulation, protection of crop safety etc. We suggest controlling the growth of cultivated land, delimiting the redline for the protection of basic farmland, transforming middle and low yield fields, building high yield fields, and orderly withdrawing non-cultivated land. We should carry out artificial replenishment to maintain the water volume of terminal lakes such as Ebinur Lake and Manasi Lake. The stability and safety of rivers, lakes, wetlands, and the surrounding forest grasslands should be maintained, and the research and protection of the natural reserves also needs to be strengthened. Main functional zoning and ecological functional zoning should be implemented, and the red line of ecological protection should be delimited and implemented. According to the characteristics of the oasis system, we should arrange the life, production, and ecological space rationally, strengthen the security of ecological water requirements from fragile ecological areas, and conserve the ecological space safety. We should promote the confirmation of rights regarding the lakes, mountains, water, field, forests etc.; strengthen the control of the use of the land; and coordinate the land between the autonomous region and the Corps.

\subsection{Coordination of "two kinds of resources" and "two markets" to promote the transformation of mineral resources from local mining to intensive processing}

We suggest making full use of the Eurasian Continental Bridge and the Silk Road Economic Belt to coordinate domestic and international mineral resources. The mining and primary processing of mineral resources inside the region may affect water resource protection, water conservation, windbreaks, and sand fixation. Combined with the local coal, oil, and iron and other dominant resources, we should strengthen the mining and primary processing of mineral resources outside the region to reduce the associated maintenance pressures. Making full use of the advantages of wind energy, light energy, and coal resources 
could result in complementary power sources such as wind power, photoelectric, thermal power, and hydropower. With these energy advantages, we should develop high load energy industries, such as electrolytic aluminum, and continuously improve the proportion of clean energy. The oil and gas pipelines in central Asian and Russia, Eurasian Continental Bridge, and other passageways can be used to establish the national strategic mineral resources reserve base in the Tianshan Mountain Northern Slope Economic Belt, which is mainly composed of oil and natural gas. The energy security capacity in Beijing, Tianjin, Hebei, and central and east China would be improved by using passageways such as the west-east natural gas transmission, west-east oil transmission, and west-east power transmission. We should give full play to the convergence and leading role of the Tianshan Mountain Northern Slope Economic Belt in central Asia, Europe, China, and southeast Asia, and coordinate the international and domestic market to promote the transformation from the mineral dominated product trade to pluralistic and complex trade that includes products, technology, and services. Relying on areas such as Urumqi, Alataw Pass, Horgas Pass, and Karamay, we suggest establishing a large commercial logistics center and product intensive processing base. By actively taking advantage of the opportunity to construct the Silk Road Economic Belt, we should improve the quality and performance of the product, dissolve excess capacity, and vigorously promote the rapid development of frontier trade and the import and export of middleand-high-end products that are intensively processed.

\section{Green development strategy of industrial economy}

We should promote the conversion of the dominant resources and optimize the industrial structure to implement the strategy of green industry and circular economy. Giving full play to the advantages of resources does not mean sacrificing the ecological environment; we suggest establishing a strict environmental access system, eliminating backward production capacity, building green mines, driving green superior resources, and promoting the transformation and upgrading of the green industry. We should optimize three production structures and the internal structure of the key industries, optimize the industrial spatial layout and the industrial structure of key regions, promote the coupling of industrial chain extension, and improve the level of the circular economy. Strategic emerging industries, such as new energy, also need to be developed vigorously. With the advantages of passageways and resources, the modern logistics industry and the tourism pillar industry are becoming increasingly stronger.

\subsection{Optimization of the industrial structure and giving full play to resource advantages on the basis of the ecological environment bearing capacity}

The proportion of tertiary industries, such as the modern logistics and tourism industries, which reflect the advantages and characteristics of regional resources, need to be improved. We suggest strengthening the logistics infrastructure, building modern logistics networks, and highlighting key areas such as the Urumqi Economic Development Zone, Khorgos Special Economic Development Zone, and the Bole Border Economic Cooperation Zone. We propose that the integration of tourism resources be strengthened, and the level of tourism products be improved. By promoting the subdivision of tourism products, the tourism product system could be perfected. With the improvement in the service level of tourism, the pillar industry of tourism may be cultivated. The tourism market, including the border trade tour, port tour, and Silk Road, should also be expanded. The scale of mining, petrochemical, coalification, coal-fired power, iron and steel, cement, electrolytic aluminum, coke, textiles and clothing, food processing and other industries with high water consumption, high energy consumption, heavy pollution, and great ecological impact should be controlled. We should avoid excessive heavy-duty industry, improve the equipment and technology level and industrial efficiency, and optimize industrial spatial layout and the relationship between the industry and the city. The excessive agglomeration of heavy industry should be avoided, and the heavy industry should not be close to the urban community. Industrial water saving, energy saving, consumption reduction, and pollution reduction still need to be further promoted. The production efficiency and the water-saving level of the first industry should be increased, and the "reduce the land and water" project needs to be carried forward vigorously. In oasis-desert transitional zones and severely overmined groundwater areas, non-cultivated land and low-yield fields should be returned to grasslands and forests. The construction of ecological agriculture and the characteristic organic agriculture should be strengthened to reduce the effects of chemical fertilizer and pesticide application on the environment.

\subsection{Increasing the construction of green mines for major minerals and vigorous promotion of the construction of green cities}

We suggest making full use of the experience of the national green mine pilot, and vigorously promoting the construction of sustainable, efficient, and environmentally friendly green mines. The existing pilot experience of green mines for products such as iron, copper, nickel, gold, and other minerals, should be spread. We should carry out pilot projects of green mines, such as coal mines and lead-zinc mines, as soon as possible. Regulations and safeguards regarding the exploitation and utilization of resources, the protection of the ecological environment, and so on should be improved constantly. The level of equipment and technology should be improved, including that of mining. The mining recovery rate, mining dilution rate, mineral recovery rate, and comprehensive utilization ratio of the main mines should 
reach an advanced level in China. It is at the domestic leading level in terms of energy saving, environmental protection, land reclamation, and so on. The construction of green cities should be continue vigorously. Pilots of low carbon cities in Karamay and Changji, and experiences of energy saving building in Turpan, should be popularized. The planning and protection of urban park green spaces should be strengthened. When building "green islands" and "green corridors" in cities, the priority should be given to local species with quality of water saving, drought tolerance, salt tolerance, and wind resistance measures. Clean energy replacement should be continuously implemented and the intensity of air pollution control should be increased. The integration of cities and industries, the project of "shifting from the second industry to the third economy", and moving the coupling industries from the suburbs to industrial parks should be promoted to develop green traffic and promote green living. The experiences of reusing intermediate water in Urumchi could be popularized, and the construction of facilities for reusing urban intermediate water should be strengthened. Energy saving buildings should be developed to make full use of luminous energy resources.

\subsection{Promotion of clean production in a global manner and development of the circular economy}

A clear production audit should be carried out to improve the level of clean production. We should expand the scope of the transparent production audit for agricultural demonstration (film recycling, etc.) and key enterprises, so that clear production in most industries, such as steel, cement, chemical, petrochemical, and non-ferrous metals, will reach an advanced level in China. The establishment of regional or enterprise clear production standards or requirements should be accelerated for high water consumption, high material consumption, high energy consumption, and heavy pollution industries or enterprises without clear production standards. Priority should be given to the strengthening of the control of water consumption, energy consumption, persistent organic pollutants (POPs), volatile organic compounds (VOCs), heavy metals and other core regional sensitive indicators. These indicators may have great potential to increase or impact persistence and damage. Aiming at the key areas of and weak links in energy saving and emission reduction, advanced technology and equipment should be adopted to accelerate the transformation of clearer production technology. The management level of energy intelligence should be enhanced. The construction of wind power in Alataw Pass, Dabancheng, and Xiaocao Lake should be accelerated, and the development of photovoltaic power generation in Turpan should be promoted vigorously to increase the proportion of renewable energy utilization. The comprehensive utilization of resources should be strengthened to continuously promote circular development [1]. With the principle of reduction, reuse, and resource utilization, the establishment of the circular industrial system should be accelerated to promote the symbiosis and cooperative use of links between enterprises, parks, industries, and regions. The mode of circular production should be fully implemented. The promotion of product manufacturing, energy conversion, waste disposal, recycling, resource utilization, and other functions in industries such as the metallurgical petrochemical industries should be carried forward. Horizontal coupling, ecological links, supply of raw materials, and sharing of resources between industries need to be strengthened. To improve the resource output rate and comprehensive competitiveness of parks, the circular transformation of various parks should be promoted, thereby realizing the coupling of productive process and poly-generation.

\section{Priority strategy for ecological environment protection}

We suggest maintaining regional ecological security, improving regional environmental quality, and implementing the priority strategy of ecological environment protection. The demand of ecological water should be guaranteed, the ecological land should be protected, and the rehabilitation of vital ecosystems should be promoted. We should strengthen the supervision of ecological risk in the development of resources and the research on climate change. The construction, maintenance, and management of environmental infrastructure should be strengthened. The emission of major pollutants in key areas should be controlled more tightly to curb various types of environmental pollution and to continuously increase the quality of the environment. The prevention of environmental risk should be strengthened in key industries, parks, and mining areas.

\subsection{Promotion of ecosystem rehabilitation and enhancement of the service function of the ecosystem}

Water conservation, windbreaks, biodiversity conservation, and the protection of other ecological functions should be taken as the basis from which to actively build the regional ecological protection system. The regional ecological protection system, which addresses air, lakes, wetlands, and protected forests, should integrate mountains, oases, and deserts. The scope of water conservation areas in the Tianshan forest grassland should be expanded so as to include it in the management of the national key ecological functional areas. The intake area of the Tianshan Mountain Northern Slope Economic Belt should strengthen support of the Aletai diversion area to protect and construct water conservation features in the upper reaches. In the inland river basin, the guarantee of ecological water demand and the conservation of desert vegetation in the lower reaches need to be improved.

It is proposed to actively encourage natural forest protection, the "Three Norths" protection forest, the return of farmland to 
forest and grazing to grassland, wetland protection, and other key ecological constructions [2]. A sand prevention and control project in the southern margin of the Junggar basin and the protection and restoration of forest vegetation in the valley of the Tianshan Mountain northern slope should be implemented. The protection of ecological water, such as important rivers, lakes, wetlands, and farmland shelterbelts, needs to be strengthened. The protection of the following areas should be enhanced: forest and grassland in the upper reaches of inland rivers; natural oases, farmland shelterbelt networks, and the oasis-desert transitional zone in the middle reaches; and rivers, lakes, wetlands and the surrounding ecological land. The protection of forest grassland vegetation should be strengthened, the scope of water conservation in mountainous areas should be expanded, and water conservation should be improved. The windbreak and sand fixation functions could be strengthened based on the construction of farmland shelterbelt networks, natural oases on the periphery of artificial oases, wetlands of rivers and lakes, surrounding vegetation, and desert vegetation. The focus is to strengthen the function of biodiversity conservation based on the construction of nature reserves.

We propose insisting that the principle of constructing the ecological district be applied, and implementing a basic grassland protection institution. The protection of grasslands, wetlands, shrubs, forests, and other ecosystems should be strengthened [3], and the protection of key ecological functional areas needs to be promoted. To encourage natural recovery, we suggest increased closing of hillsides for afforestation, returning grazing land to grassland, and returning farmland to lakes and wetlands. It is suggested that forest and animal husbandry is coordinated, forests are managed scientifically, and the protection and recovery of forests is strengthened. With the establishment of a new ecological industrial belt combined with grass, agriculture, and livestock, ecological systems such as mountains and deserts can be recuperated. We suggest protecting the naturally protected forests in mountainous areas and strengthening the forest afforestation. To enhance water conservation ability and prevent soil erosion, valley vegetation should be restored, the balance of grass and livestock should be maintained, and grassland protection should be strengthened. It is further suggested that the protection of shrubs and grasslands in oases and oasis-desert transitional zones is strengthened to prevent desertification.

\subsection{Strengthening of the construction and management of environmental infrastructure and continuous improvement of the quality of the regional environment}

The improvement of air environmental quality should be promoted, and the emission of main pollutants should be reduced. The protection of ecological water demands should be improved and ecological areas should be expanded to reduce the source of particulate matter and its impact on agricultural production and the urban living environment. The layout of industrial parks and cities should be optimized to reduce the impact of $\mathrm{NO}_{2}$ and particulates, emitted from industrial parks, on the urban living environment. To optimize the energy structure, it is proposed that cogeneration be strengthened, and clean coal technology, low nitrogen combustion technology, supercritical and ultra-supercritical power generation technology, etc. be adopted. $\mathrm{SO}_{2}$ and $\mathrm{NO}_{x}$ emissions and soot should be strictly controlled. The control of $\mathrm{SO}_{2}$ emissions should focus on industries such as electric power, thermal production and supply, non-ferrous metal smelting and rolling processing, ferrous metal smelting, and rolling processing. The control of $\mathrm{NO}_{x}$ emissions should focus on industries such as power, thermal production and supply, non-metallic mineral products, chemical raw materials, and chemical products manufacturing. The regulation of VOCs, heavy metals, and other characteristic pollutants should be strengthened. It is proposed that facilities for desulfurization, denitrification, and dust removal be constructed. The regional and industrial characteristics should be considered during the construction of facilities, and the cost of operation and maintenance should also be controllable.

The total water pollutant emissions in Ebinur Lake, Shuimo River, Chaiwopu Lake and other basins should be controlled, and environmental supervision should be strengthened. Water environment management should be transformed from water quality management to water ecological management. The combined management of water and land should be transformed into the comprehensive management of water and land. Functional zoning of the water ecological environment should be implemented, and environment standards for different types of water should be formulated. The control of the total water pollutant emission in each basin and the establishment of an index system for the total control of water pollutant emissions in river basins are proposed. The ecological industrial parks should be set up to carry out unified collection and batch treatment of pollutants from industrial sources. Chemical oxygen demand (COD) and ammonia nitrogen emissions should be controlled. The application of chemical fertilizers and rural breeding should be controlled. The supporting sewage pipe network and sewage treatment facilities in countrysides should be improved. The construction of urban sewage treatment plants need to be strengthened. By taking chemical fiber and papermaking industries as the core, the adjustment of industrial structure should be actively promoted The management and control of the characteristic pollutants based mainly on heavy metals and POPs should be strengthened. The construction and transformation of urban sewage treatment facilities should be accelerated, and the water pollution in industrial agglomeration areas should be harnessed centrally. Online monitoring should be carried out to strengthen the supervision of pollution treatment facilities.

We suggest carrying out soil pollution prevention and control, implementing the planning of soil environmental protection, and 
clarifying the strategy control, utilization, and protection strategies for soil zoning. Priority should be given to protecting areas such as main grain producing areas; bases for vegetable, melon, and fruit production; and centralized drinking water sources. Soil monitoring and environmental risk assessment of soil pollution should focus on areas such as sewage irrigation areas, urban polluted areas, waste dumps site, wastelands, and areas around seriously polluted industrial and mining enterprises to promote the control and restoration of polluted areas. The increase in the soil pollution must be strictly controlled, and access requirements for industries that have a great influence on the quality of the soil environment must be increased.

\subsection{Strengthening of the risk prevention of the ecological environment and improvement of the level of ecological environment safety}

The prevention of environmental risks in key industries and parks should be strengthened. In key industries and parks, the construction of environmental risk monitoring, warnings, and prevention capacity should be strengthened. The following industries and areas should become the focus: coalification, iron and steel, petrochemical, metallurgical etc.; Kuitun-Dushanzi Economic Development Zone, Eastern Junggar Basin Economic Development Zone, Shuimogou Industrial Zone, Miquan Industrial Zone, Shanshan Chemical Industrial Park, Shihezi Industrial Zone etc. In populated areas, drinking water sources, trans-border rivers, and other sensitive areas, the prevention, management, and control of major environmental risks should be strengthened. It is proposed to establish an environmental early warning and emergency command system with upper and lower linkage and quick response.

The development of resources and the risk supervision of the ecological environment in mining areas should be strengthened. To prevent land degradation, the protection of land sources in city outskirts, key mining areas, and surrounding lakes should be strengthened. The rational and orderly mining of coal mines prevents groundwater drainage, surface vegetation destruction, and other detrimental effects, and controls land desertification and vegetation degradation. The oil pollution of soil and groundwater caused by oil exploitation should be prevented, and the treatment, management, and control of oily wastewater should be strengthened. The protection of desert vegetation and soil around the iron ore mining area should be strengthened, and the scope and intensity of disturbances should be controlled. The comprehensive utilization of industrial solid wastes such as gangue, fly ash, metallurgical, chemical residues, and tailings should be promoted. The capacity of managing and controlling environmental risk in tailings depots should be improved to prevent the risk of secondary pollution in the processes of solid waste disposal and utilization.

We propose an active response to climate change. Greenhouse gas emissions are controlled by optimizing the energy structure and increasing the carbon sequestration of forests, grasslands, and wetlands. We propose the strengthening of the responsibility of the assessment of $\mathrm{CO}_{2}$ emission reduction targets and the establishment of the supervision of key industries such as energy and transportation. The pilot demonstration of low-carbon communities, industrial parks, and near-zero carbon emission zones should be carried forward. In addition, we suggest studying the system of total carbon emission control and quota and the key problems of the carbon emissions trading of the west-to-east power transmission.

\section{Innovation strategy of institutional mechanism reform}

We suggest reforming and improving the system of ecological civilization construction, innovating the coordination mechanism of the ecological environment, and proposing the focal point for the structural reform of the ecological civilization construction system. It is advised to establish the overall framework of inter-regional ecological environment cooperation, and innovate the system of basin cooperation between China and Kazakhstan, inter-regional cooperation between water transfer zones and water receiving areas, overall planning of inland river basins, coordination of autonomous regions and corps, and cooperation between different cities and counties. The system, integrity, and synergy of the ecological civilization construction institution should be increased, and a complete system of systematic and integrated ecological civilization should be established.

\subsection{Innovation of the regional and watershed ecological environment cooperation mechanism}

It is suggested to establish and improve the inter-regional ecological environmental cooperation mechanism, and coordinate the water diversion project for the cross-border rivers between China and Kazakhstan, the west part of Tianshan Mountain, the Ertix River, and the Kashi River. Moreover, the interurban relationship, relationship between the local government and the corps, and the relationship between cities and districts could also be coordinated. It is proposed to perfect the policies and regulations, set up the comprehensive management coordinating institution, and establish the coordination and dispute settlement mechanism of the Tianshan Mountain Northern Slope Economic Belt. The setting up of a special group for reform or a leadership group in the comprehensive management coordinating institution could be considered. The group may be called the special group on the reform of the economic system and the ecological civilization system in Xinjiang, or the leading group on promoting the construction of the core areas of the Silk Road economic belt in Xinjiang. As the core area, it also could be incorporated into 
the central "Belt and Road Initiative" construction work leading management group when conditions are ideal.

\subsection{Establishment and perfection of the eight systems of ecological civilization construction}

The implementation plan for the reform on ecological civilization system can be proposed based on the requirements of the general reform planning for the national ecological civilization system and the actual situation of the Tianshan Mountain Northern Slope Economic Belt. Moreover, the implementation plan should be suitable for the Tianshan Mountain Northern Slope Economic Belt. The trading system, land management rights, and the system of classified ownership of energy resources could be established based on the confirmed rights of the water resources, forests, grasslands, lakes and other natural resources assets. The ecological protection red line should be strictly delimited and observed. By taking Tianshan Mountains, Yili River Valley, Silk Road Economic Belt (China, Kazakhstan, and Kyrgyzstan) and other regions as the core, it is proposed to explore the start of the pilot National Park. The spatial planning of the Tianshan Mountain Northern Slope Economic Belt will be based on exploring the establishment of a unified and standardized spatial planning mechanism. The total amount of construction land and the urban boundary will be controlled based on the setting up of the supporting policy for the implementation of the "reduce the land and water" project. The supporting policy for the rehabilitation of the natural ecological system should be established. This is a system involving compensable resources and the ecological compensation system that should be improved. A modern environmental governance system should be established, as well as a cooperation mechanism for the joint prevention and control of regional pollution. In particular, this applies to the air pollution prevention and control cooperation mechanism in Wuchang, Kuiduwu, and other key areas, as well as the sandstorm, salt, and dust joint prevention and control mechanism. The latter mechanism covers the area from the Tianshan Mountain Northern Slope to Urumqi. A green ecological agriculture subsidy system should be established, and the utilization of agricultural film, straw, and other agricultural waste resources should be encouraged. The market system of environmental governance and ecological protection needs to be perfected. To improve the pilot carbon emissions trading, priority could be given to metal smelting, oil processing, electric heating, and other industries. Then, the scope may be gradually expanded to agroforestry. The carbon emission trading model and mechanism and the carbon emission accounting for exporting electricity should be given priority for exploration in the eastern part of the Junggar Basin and the Hami area. Priority should be given to carrying out the pilot pollution emission trading in heavy pollution industries such as coal chemical, petrochemical, metal mining, and smelting. First, exploration of inter-district pollution emission trading should be carried out in Wuchang, Kuiduwu, Changji, Shimasha, and the basins of Ebinur Lake and Manas River. Priority should be given to the carrying out of the pilot water right trading in the eastern Junggar basin, Turpan, and the basins of Ebinur Lake and Manas River. The construction of green product system of melon, fruit, vegetables, livestock products, and aquatic products should be emphasized. A system of performance assessment and accountability for ecological civilization should be established. The black (coal, oil), white (cotton, salt), and red (industrial tomato) industries should be transformed to green and upgraded. In areas with rapid growth of cultivated land, the protection of basic farmland, construction of high-yield fields, recharge of groundwater, and protection of the ecological water requirements of the rivers and lakes should be the focus. The amount of water and the level of water saving should be taken into consideration in areas of severe groundwater overexploitation. The protection of ecological land and ecological water demand should be emphasized in area of severe ecological degradation.

\section{Strategy of domestic guidance, connecting abroad, and opening to the west}

The "two kinds of resources" and "two markets" should be coordinated. According to domestic guidance regarding the connection of foreign countries, the Tianshan Mountain Northern Slope Economic Belt could be opened to the west. There are good resources, such as energy and grain, in the west of the Tianshan Mountain Northern Slope Economic Belt. Moreover, capital, equipment, technology, talent resources, and abundant products are in the east of the Tianshan Mountain Northern Slope Economic Belt. Connecting domestic and foreign resources and markets, domestic guidance, and connection with foreign countries can effectively fill in gaps of development in the Tianshan Mountain Northern Slope Economic Belt. It is necessary to strengthen the mutually beneficial cooperation with the countries in the west and central Asia, central Europe, and countries along the Silk Road. We suggest strengthening the linkage and cooperation between the departments and innovating the mode of cooperation.

\subsection{Increase in the strength of opening up to the west}

It is proposed to strengthen the cooperation with related countries and innovate the mode of cooperation. There are rich resources of energy minerals and broad markets in Central Asia, South Asia, West Asia and Europe. The developed countries in Europe also have the advantages of technology and management. In Khorgos, Alataw Pass, Urumchi, and other ports, the single structure of "import natural gas and export electrical machinery" should be optimized. The trading structure should be developed to high- and middle-end and diversified industries, which covers equipment, technology, and services. The proportion of leading 
enterprises in the import and export trade should be increased. The convenience of commercial logistics and storage also should be improved. This will increase the modern logistics industry and export processing industry.

We propose the building of the modern Silk Road and the corridor of Eurasia. The overall design could be strengthened from the aspects of transportation, trade, energy, culture, and so on. It would intensify the Tianshan Mountain Northern Slope Economic Belt opening up to the west. China should strengthen support of the Tianshan Mountain Northern Slope Economic Belt opening up to the west, so as to increase and promote the economic and trade cooperation relations between the Tianshan Mountain Northern Slope Economic Belt and the surrounding countries. This area should be listed as the national pilot to expand the opening up to the west. In this area, the government could implement the special policy of opening to the outside world, the more preferential border trade policy, and the policy of reducing import tariffs and taxes by half. To promote the "Coming from the west and going to the east", philosophy, a greater effort should be made to support the opening of Urumqi to the outside world, especially to the surrounding countries. Speeding up the transformation of export processing and trade logistics development, and optimizing industrial and product structures could realize industrial transformation and upgrading. The export of enterprises should guide transformation to emphasize its quality and benefits. Enterprises should be supported to expand the export of high-tech and mechanical and electrical products that have independent intellectual property rights and international competitiveness. The government should strive to create a number of international brands, strengthen the market adaptability, optimize the export structure, and improve the international competitiveness of the products.

We suggesting implementing energy diplomacy and the strategy of "going out." Enterprises should be encouraged and supported to carry out the cooperation and development of energy resources with surrounding countries in central Asia. In addition, dominant enterprises should be led to establish the development and processing base of resources overseas. The government should lead enterprises to "going out" and cooperate with local enterprises by merging, participation, and joint exploitation. It could develop and process local resources such as agriculture, oil, gas, and minerals, and drive the export of technology, equipment, materials, labor, and services. It is proposed to drive mature labor-intensive industries in eastern China to gradually shift overcapacity overseas to create "Industry echelon transfer." The government could support foreign industrial zones and civil chambers of commerce with a policy to decrease the risk of investment and management and increase the operational efficiency.

\subsection{Optimization of the direction of opening up to the west}

The opening up to the west should gradually transform from the trade of raw materials and primary products to green technology (such as water-saving irrigation technology and green mining technology), diversified services (such as finance, logistics \& storage, labor, tourism, cultural exchanges, and assistance), exchanges of standards \& concepts (such as agricultural product standards, environmental quality standards, and the concepts of sustainable development and ecological civilization transformation).

It is necessary to build the financial center of the Silk Road Economic Belt. The government should actively promote the planning and construction of the regional financial center, and build a multi-level financial system with Urumqi as the core and Yili as the sub-center. The settlement of local currency between the RMB and the surrounding countries of Central Asia should be promoted. The pilot of the offshore RMB business and the cross-border RMB business in the International Border Cooperation Center between China and Kazakhstan could be conducted in Khorgos. It is also proposed that the construction of the original area of the international financial port in Khorgos is explored.

In particular, the storage and logistics for airports in Urumchi and ports in Khorgos and Alataw Pass should be constructed. The construction of stations should be accelerated to improve the efficiency of freight traffic and customs clearance. The construction of railway freight trains in Central Asia, Western Asia, and Europe should also be promoted. The government should make full use of the advantages of the four special customs regulatory zones, such as the Urumqi bonded area, and continuously improve the convenience of commercial trade and the efficiency of logistics.

The import and processing of raw materials, such as oil, natural gas, iron ore, bauxite and other metals, and non-metallic minerals - including grain, cotton, leather, wool, and timbershould be strengthened, along with the processing and export of food, textile products, mining machinery, and electronic products. The construction of the foreign trade processing base in Yining, Bole, Shihezi, Karamay, and other regions should be emphasized.

We advise the acceleration of the development of crossborder tourism. Tourism cooperation between border states and foreign countries should be promoted. We propose the development of the international boutique tour route with surrounding countries, as well as cross-border tourism and characteristic tourism. By making full use of the world heritage resources of Tianshan Mountain and Silk Road, the government should actively promote and develop the boutique tour route with the Tianshan Mountain and Silk Road as the core. Moreover, the government should facilitate cross-border tourism.

We suggest improving the investment management and strengthening the cooperation of production capacity. The system and mechanism of foreign investment and overseas investment management should be improved to increase the level of 
convenience and strengthen the supervision and management. The construction of an international capacity cooperation system mechanism should be accelerated to encourage the manufacturing industry to promote mutually beneficial production capacity cooperation with a double multilateral mechanism. It may cover power transmission and transformation equipment, new energy equipment, engineering machinery, and other manufacture industries. The steel, cement, and other industries should be supported to cooperate with surrounding countries regarding production capacity.

\subsection{Strengthening of support to open up the west}

The support of institutional mechanisms, policies, and systems should be strengthened to construct the basic platform for opening up to the West. The exploration should focus on the construction of China-Central Asia Free Trade Area, the special customs supervision area, and other related institutional mechanisms.

The management mechanism should be optimized and the financial innovation should be strengthened. Establishing the "experimental field" of western China actively opening-up to the outside world and the "upside down" mechanism that integrates the new global pattern would realize the target of transformation and upgrading of the open economy. This facilitates a free trade test area with an international standard of investment and trade convenience, free currency exchange, efficient and convenient supervision, and regulation of the legal environment.

The innovation and upgrading of the customs special regulatory areas should be accelerated to promote the development of the open economy, reform, and opening up. The industry should be encouraged to extend to the high end of the industrial chain with activities such as research \& development, sales, logistics, and settlement. It will promote the deep integration of the manufacturing industry and productive service industry, as well as the transformation of foreign trade to excellence. The integrated optimization scheme for the special customs supervision areas should be implemented, and central and western regions that meet these conditions should be supported to set up the comprehensive bonded zone.

\section{References}

[1] Fu Z H, Song Z K, Chen X H, et al. Study on green development strategies for the industry in China $[\mathrm{J}]$. Strategic Study of CAE, 2015, 17(8): 16-22. Chinese.

[2] Meng W, Shu J M, Zhang L B, et al. Study on the goals and key tasks of eco-civilization construction in the 13th Five-Year Plan period [J]. Strategic Study of CAE, 2015, 17(8): 39-45. Chinese.

[3] Shen G F, Li S D, Wu B, et al. Study on development strategy of ecological protection and construction in China [J]. Strategic Study of CAE, 2015, 17(8): 23-29. Chinese. 